\title{
(2) OPEN ACCESS \\ Safety and tolerability of nintedanib in patients with systemic sclerosis-associated interstitial lung disease: data from the SENSCIS trial
}

\author{
James R Seibold (D) , Toby M Maher, ${ }^{2,3,4}$ Kristin B Highland, ${ }^{5}$ Shervin Assassi (1) , 6 \\ Arata Azuma, ${ }^{7}$ Laura Kathleen Hummers, ${ }^{8}$ Ulrich Costabel, ${ }^{9}$ Ute von Wangenheim, ${ }^{10}$ \\ Veronika Kohlbrenner, ${ }^{11}$ Martina Gahlemann, ${ }^{12}$ Margarida Alves, ${ }^{13}$ Oliver Distler (D) , ${ }^{14}$ \\ on behalf of the SENSCIS trial investigators
}

\begin{abstract}
Handling editor Josef $S$ Smolen

- Additional material is published online only. To view, please visit the journal online (http://dx.doi.org/10.1136/ annrheumdis-2020-217331).
\end{abstract}

For numbered affiliations see end of article.

Correspondence to Dr James R Seibold, Scleroderma Research Consultants, LLC, Aiken, SC 29803, USA: jamesrseibold@gmail.com

Received 12 March 2020 Revised 15 June 2020

Accepted 29 June 2020 Published Online First 5 August 2020

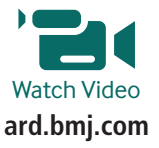

Check for updates

(c) Author(s) (or their employer(s)) 2020. Re-use permitted under CC BY. Published by BMJ.

To cite: Seibold JR, Maher TM, Highland KB,

et al. Ann Rheum Dis

2020;79:1478-1484.

\section{ABSTRACT}

Objectives To characterise the safety and tolerability of nintedanib and the dose adjustments used to manage adverse events in patients with systemic sclerosisassociated interstitial lung disease (SSC-ILD).

Methods In the SENSCIS trial, patients with SSC-ILD were randomised to receive nintedanib $150 \mathrm{mg}$ two times per day or placebo. To manage adverse events, treatment could be interrupted or the dose reduced to $100 \mathrm{mg}$ two times per day. We assessed adverse events and dose adjustments over 52 weeks.

Results A total of 576 patients received nintedanib $(n=288)$ or placebo $(n=288)$. The most common adverse event was diarrhoea, reported in $75.7 \%$ of patients in the nintedanib group and $31.6 \%$ in the placebo group; diarrhoea led to permanent treatment discontinuation in $6.9 \%$ and $0.3 \%$ of patients in the nintedanib and placebo groups, respectively. In the nintedanib and placebo groups, respectively, $48.3 \%$ and $12.2 \%$ of patients had $\geq 1$ dose reduction and/or treatment interruption, and adverse events led to permanent discontinuation of the trial drug in $16.0 \%$ and $8.7 \%$ of patients. The adverse events associated with nintedanib were similar across subgroups defined by age, sex, race and weight. The rate of decline in forced vital capacity in patients treated with nintedanib was similar irrespective of dose adjustments.

Conclusions The adverse event profile of nintedanib in patients with SSc-ILD is consistent with its established safety and tolerability profile in patients with idiopathic pulmonary fibrosis. Dose adjustment is important to minimise the impact of adverse events and help patients remain on therapy.

\section{INTRODUCTION}

Systemic sclerosis (SSc) is a heterogeneous autoimmune disease characterised by immune dysregulation, microvascular damage, and organ fibrosis. ${ }^{1}$ Interstitial lung disease (ILD) is a common manifestation of SSc and the leading cause of death in patients with SSc. ${ }^{2}$ Nintedanib, an intracellular inhibitor of tyrosine kinases, ${ }^{3}$ has been approved for the treatment of idiopathic pulmonary fibrosis (IPF) and systemic sclerosis-associated interstitial lung disease (SSc-ILD). In the placebo-controlled INPULSIS trials in patients with IPF, SENSCIS trial in patients with SSc-ILD, and INBUILD trial in
Key messages

What is already known about this subject?

- The adverse event profile of nintedanib in patients with interstitial lung diseases is characterised mainly by gastrointestinal adverse events, particularly diarrhoea, which in most cases are of mild or moderate intensity and do not lead to treatment discontinuation.

What does this study add?

- The adverse events associated with nintedanib in patients with systemic sclerosis-associated interstitial lung disease (SSC-ILD) are similar across subgroups defined by age, sex, race and weight.

- Patients with SSc-ILD who have a predisposition to gastrointestinal or intestinal events are not more likely to have gastrointestinal adverse events when treated with nintedanib than patients without such a predisposition.

- The rate of decline in forced vital capacity is similar in nintedanib-treated patients irrespective of dose adjustments used to manage adverse events.

How might this impact on clinical practice or future developments?

- The dose adjustments used to manage adverse events in the SENSCIS trial can be implemented in clinical practice to minimise the impact of adverse events and help patients with SSc-ILD remain on nintedanib.

patients with various fibrosing ILDs with a progressive phenotype, nintedanib reduced the progression of ILD, as demonstrated by a reduction in the rate of decline in forced vital capacity (FVC) over 52 weeks. ${ }^{4-6}$

The adverse event profile of nintedanib in patients with ILDs is characterised mainly by gastrointestinal adverse events. ${ }^{4-6}$ Gastrointestinal issues are also a common problem associated with SSc and with treatments commonly used for SSc. ${ }^{7}$ We used data from the SENSCIS trial to characterise further the safety and tolerability of nintedanib in patients 
with SSc-ILD and to describe how adverse events were managed during this trial.

\section{METHODS}

\section{Trial design}

The design of the SENSCIS trial has been published, together with the trial protocol. ${ }^{5}$ Briefly, patients with SSc with onset of first non-Raynaud symptom $<7$ years before screening, extent of fibrotic ILD $\geq 10 \%$ on a high-resolution CT scan, FVC of $\geq 40 \%$ predicted and diffusing capacity of the lung for carbon monoxide $30 \%-89 \%$ predicted were randomised $1: 1$ to receive nintedanib $150 \mathrm{mg}$ two times per day or placebo. Patients on prednisone $\leq 10 \mathrm{mg} /$ day (or equivalent) and/or stable therapy with mycophenolate or methotrexate for $\geq 6$ months prior to randomisation were allowed to participate. Patients with investigator-reported significant pulmonary hypertension $(\mathrm{PH})$ (defined as previous clinical or echocardiographic evidence of significant right heart failure, history of right heart catheterisation showing a cardiac index of $\leq 2 \mathrm{~L} / \mathrm{min} / \mathrm{m}^{2}$ or $\mathrm{PH}$ requiring parenteral therapy with epoprostenol/treprostinil) were excluded. Patients without protocol-defined significant $\mathrm{PH}$ were allowed to participate. Treatment interruptions (for $\leq 4$ weeks for adverse events considered related to trial medication or $\leq 8$ weeks for other adverse events) and dose reductions to $100 \mathrm{mg}$ two times per day were recommended to manage adverse events. After resolution of the adverse event, nintedanib could be reintroduced or the dose increased back to $150 \mathrm{mg}$ two times per day. Specific recommendations were provided to the investigators for the management of diarrhoea and hepatic enzyme elevations (figure 1). Adverse events were reported by the investigators irrespective of causality and were coded according to the Medical Dictionary for Regulatory Activities V.21.1. Blood samples for pharmacokinetic analyses were collected at weeks 4 and 24 , just before drug administration.

\section{Analyses}

Compliance with trial medication was calculated as the number of capsules taken multiplied by 100 and divided by the number of capsules that should have been taken. Dose intensity was defined as the amount of drug administered divided by the amount of drug that would have been received if the dose of $150 \mathrm{mg}$ two times per day had been administered over the 52-week treatment period, or until permanent treatment discontinuation. The annual rate of decline in FVC (mL/year) over 52 weeks (373 days) in patients treated with nintedanib was assessed in subgroups based on dose adjustment, using a random coefficient regression model (with random slopes and intercepts), including effects for antitopoisomerase I antibody status, sex, baseline FVC $(\mathrm{mL})$, age and height and baseline-by-time, treatment-bysubgroup and treatment-by-subgroup-by-time interaction terms.

We analysed adverse events reported over 52 weeks (or until 28 days after the last intake of trial drug in patients who

A

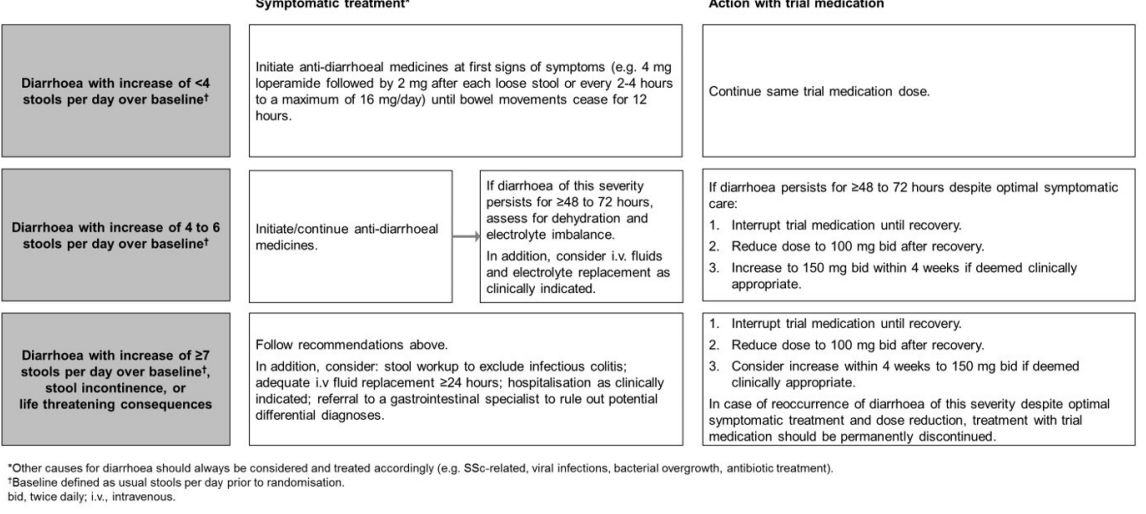

B

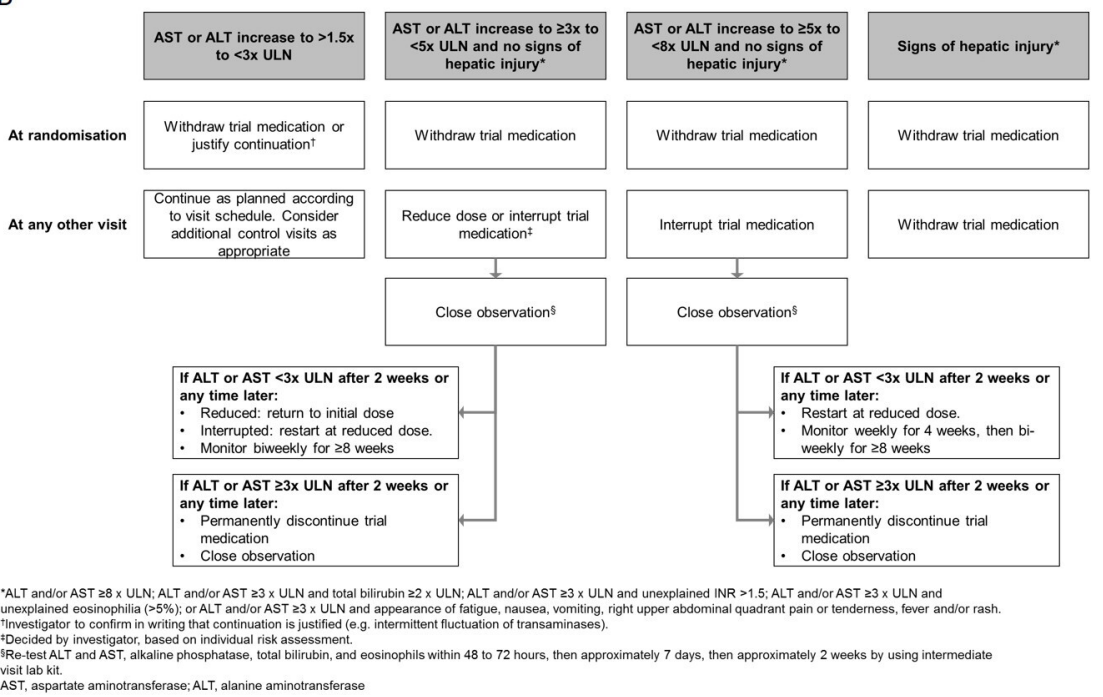

Figure 1 Algorithm for the management of diarrhoea adverse events (A) and hepatic enzyme elevations (B) in the SENSCIS trial. SSc, systemic sclerosis; ULN, upper limit of normal. 
discontinued trial drug before week 52). Based on the mechanism of action of nintedanib ${ }^{3}$ and data from trials in patients with IPF, ${ }^{4}$ we present data on diarrhoea, hepatic adverse events and liver enzyme and bilirubin elevations, bleeding and cardiovascular adverse events. The proportions of patients with any adverse events; with severe, serious and fatal adverse events; with adverse events leading to treatment discontinuation; with hepatic adverse events; and with the most frequent adverse events were assessed in subgroups by age at baseline $(<65$ years and $\geq 65$ years), sex, weight at baseline ( $\leq 65 \mathrm{~kg}$ and $>65 \mathrm{~kg}$ ) and race (White, Asian and Black/African-American). Severe adverse events were defined as events that were incapacitating or caused an inability to work or perform usual activities. Serious adverse events were defined as events that resulted in death, were lifethreatening, resulted in hospitalisation or prolongation of hospitalisation, resulted in persistent or clinically significant disability or incapacity, were a congenital anomaly or birth defect or were deemed to be serious for any other reason. Gastrointestinal adverse events were analysed in patients with and without a predisposition to intestinal events (defined as a history of and/or presence at baseline of diarrhoea, bloating, constipation and/or incontinence) and in patients with and without a predisposition to gastrointestinal events (defined as a history of gastrointestinal events and/or the presence of gastro-oesophageal reflux disease, oesophageal dysphagia, malabsorption, SSc-related diarrhoea or constipation at baseline). Analyses were descriptive and based on patients who received $\geq 1$ dose of trial drug.

\section{RESULTS}

\section{Patients}

In total, 576 patients were treated. At baseline, the mean (SD) age was 54.0 (12.2) years; weight was 69.7 (15.9) kg; body mass index was $25.9(5.0) \mathrm{kg} / \mathrm{m}^{2} ; 75.2 \%$ of patients were female, 67.2\% were White and 24.8\% were Asian; $60.8 \%$ were positive for antitopoisomerase I antibody, and 51.9\% had diffuse cutaneous SSc. Most patients (97.7\%) were taking $\geq 1$ medication at baseline. Based on customised drug groupings, $79.5 \%$ of patients were taking drugs for gastric acid-related disorders; $64.1 \%$ were taking antihypertensives; $53.1 \%$ were taking therapies for pain; $49.8 \%$ were taking corticosteroids; and $30.7 \%$ were taking lowdose antithrombotic therapies. Nearly half (48.4\%) of patients were taking mycophenolate (mofetil or sodium) and $6.6 \%$ were taking methotrexate. The gastrointestinal disorders reported at screening were oesophageal dysphagia or reflux (62.7\%), vomiting or early satiety (15.3\%), constipation (12.0\%), bloating (12.0\%), diarrhoea (10.2\%) and incontinence (4.7\%).

\section{Dose adjustments and treatment discontinuations}

Over 52 weeks, $19.4 \%$ of patients in the nintedanib group and $10.8 \%$ of patients in the placebo group prematurely discontinued trial medication. Information on dose reductions and treatment interruptions over 52 weeks is shown in table 1 . Over 52 weeks, $48.3 \%$ of patients in the nintedanib group and $12.2 \%$ in the placebo group had $\geq 1$ dose reduction and/or treatment interruption. The most common reason for dose reduction or treatment interruption was diarrhoea. Dose reductions and treatment interruptions were more common among female than male patients (online supplementary table S1).

In patients who had a dose reduction after week 4 and were receiving the dose of $100 \mathrm{mg}$ two times per day at week 24 $(n=35)$, the geometric mean trough concentration of nintedanib was $11.50 \mathrm{ng} / \mathrm{mL}$ at week 4 and $6.14 \mathrm{ng} / \mathrm{mL}$ at week 24 . Among patients who did not have a dose reduction between weeks 4
Table 1 Dose reductions and treatment interruptions in the SENSCIS trial

\begin{tabular}{llc}
\hline & $\begin{array}{l}\text { Nintedanib } \\
(\mathbf{n}=288)\end{array}$ & $\begin{array}{l}\text { Placebo } \\
(\mathbf{n}=288)\end{array}$ \\
\hline Patients with $\geq 1$ dose reduction & $117(40.6)$ & $13(4.5)$ \\
\hline Number of dose reductions per patient & & \\
1 & $104(36.1)$ & $13(4.5)$ \\
\hline 2 & $13(4.5)$ & 0 \\
$>2$ & 0 & 0
\end{tabular}

Time to first dose reduction

$\begin{array}{lll}\leq 30 \text { days } & 11(3.8) & 2(0.7) \\ >30 \text { to } \leq 61 \text { days } & 20(6.9) & 4(1.4) \\ >61 \text { to } \leq 91 \text { days } & 19(6.6) & 1(0.3) \\ >91 \text { to } \leq 182 \text { days } & 34(11.8) & 4(1.4) \\ >182 \text { days } & 33(11.5) & 2(0.7) \\ \text { Patients with } \geq 1 \text { dose re-escalation following dose } & 25(8.7) & 2(0.7)\end{array}$

reduction

Patients for whom last dose was $100 \mathrm{mg}$ two times $105(36.5)$

per day

Most frequent reasons for dose reduction, $\mathrm{n}(\%)$ of dose reductions*

Adverse events considered related to trial drug by investigator

Diarrhoea $77(59.2)$

Vomiting $7(5.4)$

Alanine aminotransferase increased $\quad 5(3.8)$

Nausea $\quad 5(3.8)$

Hepatic enzyme increased

$0(0.0)$

Abdominal pain upper

$4(3.1) \quad 1(7.7)$

Weight decreased

$3(2.3)$

$3(2.3)$

$1(7.7)$

Adverse events considered unrelated to trial drug

by investigator

$4(3.1)$

$0(0.0)$

Patients with $\geq 1$ treatment interruption

$109(37.8)$

$0(0.0)$

Number of treatment interruptions per patient

1

2

$>2$

$73(25.3)$

Time to first treatment interruption

$\leq 30$ days

$>30$ to $\leq 61$ days

$>61$ to $\leq 91$ days

$\begin{array}{ll}21(7.3) & 3(1.0) \\ 15(5.2) & 6(2.1)\end{array}$

$>91$ to $\leq 182$ days

$8(6.3) \quad 8(2.8)$

$>182$ days

Duration of treatment interruption (days), mean

$(\mathrm{SD})^{\dagger}$

Most frequent reasons for treatment interruption, $\mathrm{n}(\%)$ of interruptions*

Adverse events considered related to trial drug by investigator

$\begin{array}{lcc}\text { Diarrhoea } & 75(41.2) & 12(19.4) \\ \text { Abdominal pain upper } & 19(10.4) & 6(9.7) \\ \text { Alanine aminotranferase increased } & 5(2.7) & 1(1.6) \\ \text { Hepatic enzyme increased } & 5(2.7) & 1(1.6) \\ \text { Vomiting } & 4(2.2) & 1(1.6) \\ \text { Hypotension } & 0(0.0) & 3(4.8) \\ \text { dverse events considered unrelated to trial drug } & 19(10.4) & 15(24.2)\end{array}$

by investigator

Data are $\mathrm{n}(\%)$ of patients unless otherwise stated. Dose reductions and treatment interruptions over 52 weeks are shown.

* Reasons reported in >2 patients in either treatment group are shown based on preferred terms in the Medical Dictionary for Regulatory Activities.

tTotal duration of all interruptions.

and $24(n=160)$, the geometric mean trough concentration of nintedanib was $7.75 \mathrm{ng} / \mathrm{mL}$ at week 4 and $7.60 \mathrm{ng} / \mathrm{mL}$ at week 24. Compared with patients who did not have a dose reduction, greater proportions of patients who had a dose reduction 


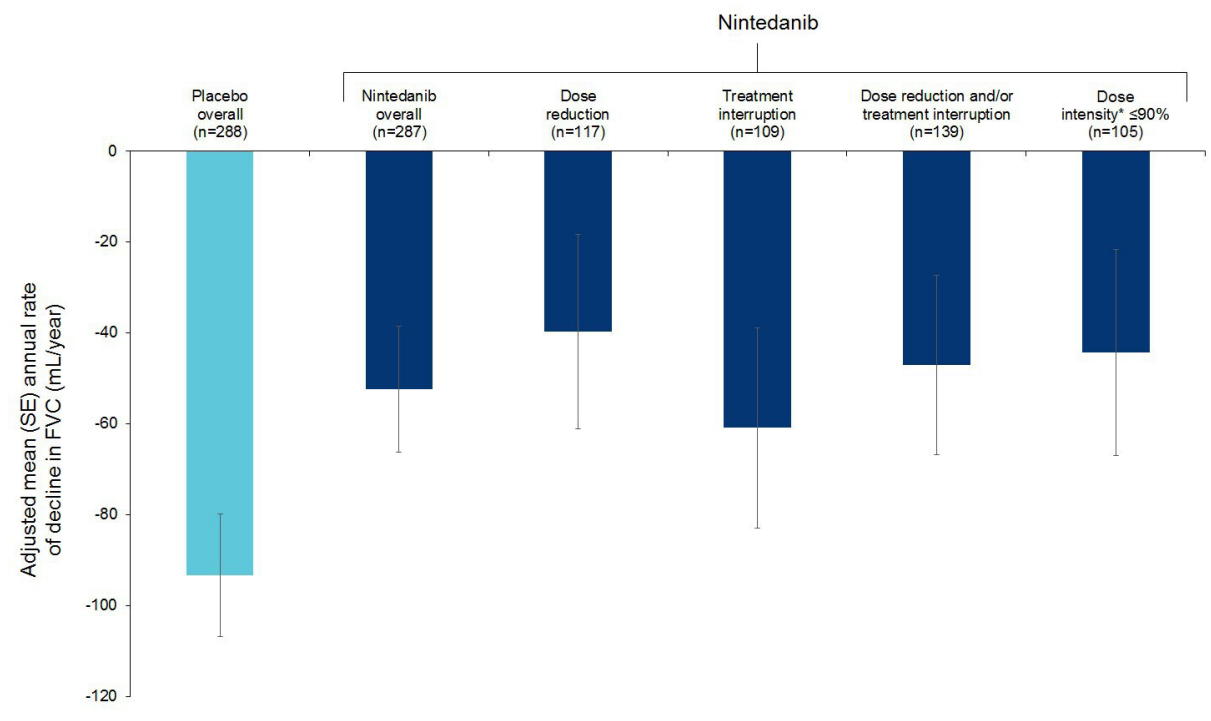

between weeks 4 and 24 had a baseline weight of $\leq 65 \mathrm{~kg}(35.6 \%$ vs $54.3 \%)$ and were of Asian race (19.4\% vs $34.3 \%)$.

Mean compliance with trial medication was $95.5 \%$ in the nintedanib group and $96.4 \%$ in the placebo group, and mean dose intensity was $90.3 \%$ and $98.4 \%$ in these groups, respectively. The median exposure to trial drug (at either dose) over 52 weeks was 12.2 months in both treatment groups. In patients treated with nintedanib, the annual rate of decline in FVC (mL/ year) over 52 weeks was similar irrespective of dose adjustments used to manage adverse events (figure 2).

\section{Adverse events}

The proportions of patients with any adverse event/s $(98.3 \%$ and $95.8 \%$, respectively) and any serious adverse event/s (24.0\% and $21.5 \%$, respectively) were similar in the nintedanib and placebo groups. The most common adverse event was diarrhoea, reported in $75.7 \%$ of patients in the nintedanib group and $31.6 \%$ of patients in the placebo group.

Weight loss was reported as an adverse event by $11.8 \%$ of patients in the nintedanib group and $4.5 \%$ in the placebo group. At week 52, the mean (SD) change from baseline in weight was $-3.22(4.54) \mathrm{kg}$ in the nintedanib group and $-0.25(4.05) \mathrm{kg}$ in the placebo group.

Adverse events reported in subgroups by sex, age, weight and race are shown in online supplementary tables S2-S5. In the nintedanib group, nausea, vomiting and hepatic events were reported more frequently in female patients, while serious adverse events were more frequent in male patients. Decreased weight and adverse events leading to treatment discontinuation occurred more frequently in nintedanib-treated patients aged $\geq 65$ than $<65$ years. Liver test abnormalities were reported more frequently in Asian patients than White patients, while nausea and fatigue were more common in White patients than Asian patients. The number of Black/African-American patients was too small to allow conclusions to be drawn about adverse events in this subgroup.

Adverse events leading to permanent discontinuation of trial drug occurred in $16.0 \%$ of patients in the nintedanib group and $8.7 \%$ of patients in the placebo group. Most of the permanent discontinuations of nintedanib were due to gastrointestinal events, particularly diarrhoea (table 2).

\section{Gastrointestinal adverse events}

Among nintedanib-treated patients who experienced $\geq 1$ diarrhoea adverse event over 52 weeks, approximately half $(51.8 \%)$ experienced onset of their first event $\leq 30$ days after initiation of treatment (table 3 and figure 3), and most (70.2\%) experienced one or two events over 52 weeks. Most (94.5\%) experienced events that were at worst of mild or moderate intensity, while $5.5 \%$ experienced $\geq 1$ event rated as severe. Most $(90.8 \%)$ of the nintedanib-treated patients who experienced $\geq 1$ diarrhoea adverse event over 52 weeks did not permanently discontinue the drug due to diarrhoea (table 3 ). Over 52 weeks, $48 \%$ of patients in the nintedanib group and $9 \%$ of patients in the placebo group began antidiarrhoeal medication (online supplementary table S6). Additional information on the treatment of diarrhoea adverse events is given in online supplementary table S7.

In both treatment groups, the proportions of patients with adverse events of nausea, vomiting and weight loss were numerically higher in patients with than without a predisposition to

Table 2 Adverse events leading to permanent treatment discontinuation in the SENSCIS trial

\begin{tabular}{llc}
\hline & $\begin{array}{l}\text { Nintedanib } \\
(\mathbf{n}=\mathbf{2 8 8})\end{array}$ & $\begin{array}{l}\text { Placebo } \\
(\mathbf{n}=\mathbf{2 8 8})\end{array}$ \\
\hline $\begin{array}{l}\text { Any adverse event(s) leading to permanent } \\
\text { treatment discontinuation }\end{array}$ & $46(16.0)$ & $25(8.7)$ \\
\hline Most frequent adverse event(s) leading to permanent treatment discontinuation* & $1(0.3)$ \\
\hline Diarrhoea & $20(6.9)$ & 0 \\
\hline Nausea & $6(2.1)$ & $1(0.3)$ \\
Vomiting & $4(1.4)$ & $1(0.3)$ \\
\hline Abdominal pain upper & $3(1.0)$ & 0 \\
\hline Alanine aminotransferase increased & $2(0.7)$ & $3(1.0)$ \\
\hline Progression of ILD & $3(1.0)$ & $28 \mathrm{days}$
\end{tabular}

Data are $\mathrm{n}(\%)$ of patients. Adverse events reported over 52 weeks (or until 28 days after last trial drug intake for patients who discontinued trial drug before week 52). *Adverse events leading to permanent treatment discontinuation in $>2$ patients in either treatment group over 52 weeks, coded according to preferred terms in the MedDRA.

†Based on MedDRA preferred term 'interstitial lung disease'.

ILD, interstitial lung disease; MedDRA, Medical Dictionary for Regulatory Activities. 
Table 3 Number, intensity and consequences of diarrhoea adverse events in patients who experienced $\geq 1$ diarrhoea adverse event in the SENSCIS trial

\begin{tabular}{lcc}
\hline & $\begin{array}{c}\text { Nintedanib } \\
(\mathbf{n}=218)\end{array}$ & $\begin{array}{c}\text { Placebo } \\
(\mathbf{n}=91)\end{array}$ \\
\hline Number of diarrhoea events & $107(49.1)$ & $54(59.3)$ \\
\hline 1 & $46(21.1)$ & $21(23.1)$ \\
\hline 2 & $24(11.0)$ & $4(4.4)$ \\
\hline 3 & $41(18.8)$ & $12(13.2)$ \\
\hline Time to first onset of diarrhoea event & & \\
\hline$\leq 30$ days & $113(51.8)$ & $49(53.8)$ \\
\hline$>30$ to $\leq 61$ days & $35(16.1)$ & $12(13.2)$ \\
\hline$>61$ to $\leq 91$ days & $25(11.5)$ & $12(13.2)$ \\
\hline$>91$ to $\leq 182$ days & $28(12.8)$ & $3(3.3)$ \\
\hline$>182$ days & $17(7.8)$ & $15(16.5)$ \\
\hline Intensity of worst event & \\
\hline Mild & $108(49.5)$ & $61(67.0)$ \\
\hline Moderate & $98(45.0)$ & $27(29.7)$ \\
\hline Severe & $12(5.5)$ & $3(3.3)$ \\
\hline Outcome of worst event & & \\
\hline Recovered & $202(92.7)$ & $86(94.5)$ \\
\hline Not yet recoveredt & $14(6.4)$ & $5(5.5)$ \\
\hline Recovered/resolved with sequelae & $1(0.5)$ & 0 \\
\hline Unknown & $1(0.5)$ & 0 \\
\hline Consequence of worst event for trial drug & $20(9.2)$ & $1(1.1)$ \\
\hline Permanently discontinued & $57(26.1)$ & $2(2.2)$ \\
\hline Permanent dose reduction & $141(64.7)$ & $88(96.7)$ \\
\hline Neither of above & & \\
\hline Advse events report & & \\
\hline
\end{tabular}

Adverse events reported over 52 weeks (or until 28 days after last trial drug intake for patients who discontinued trial drug before week 52$)$. Data are $\mathrm{n}(\%$ of patients with $\geq 1$ diarrhoea adverse event).

* Mild: awareness of signs or symptoms which are easily tolerated; moderate: enough discomfort to cause interference with usual activity; severe: incapacitating or causing inability to work or to perform the usual activities.

tThe patient has not yet returned to his/her previous health status and continues to be followed up.

intestinal events at baseline (table 4). Other gastrointestinal adverse events in the nintedanib group were reported in similar proportions of patients with and without a predisposition to intestinal events. Similar findings were observed in subgroups with and without a predisposition to gastrointestinal events at baseline (online supplementary table S8).

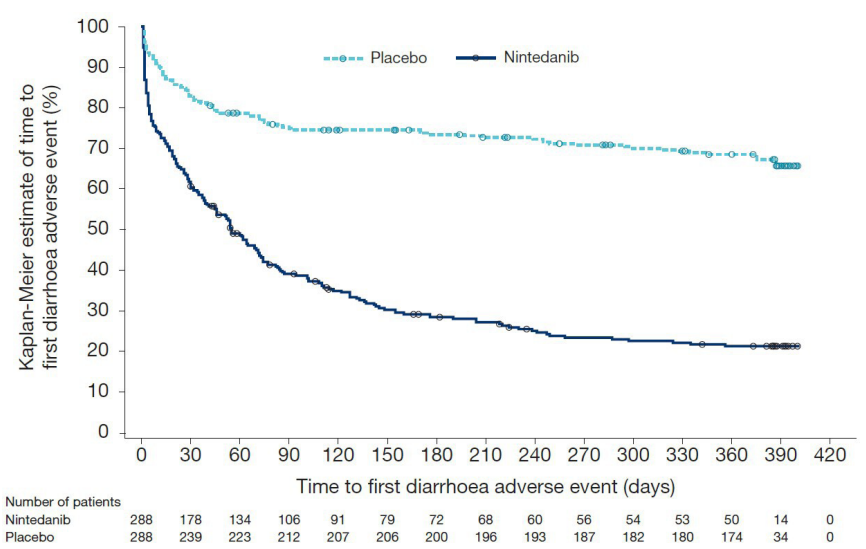

Figure 3 Time to first diarrhoea adverse event in the SENSCIS trial.
Table 4 Gastrointestinal and weight loss adverse events by predisposition to intestinal events in the SENSCIS trial

\begin{tabular}{|c|c|c|c|c|}
\hline & \multicolumn{2}{|c|}{$\begin{array}{l}\text { With predisposition to } \\
\text { intestinal events }\end{array}$} & \multicolumn{2}{|c|}{$\begin{array}{l}\text { Without predisposition to } \\
\text { intestinal events }\end{array}$} \\
\hline & $\begin{array}{l}\text { Nintedanib } \\
(n=115)\end{array}$ & $\begin{array}{l}\text { Placebo } \\
(n=114)\end{array}$ & $\begin{array}{l}\text { Nintedanib } \\
(n=173)\end{array}$ & $\begin{array}{l}\text { Placebo } \\
(n=174)\end{array}$ \\
\hline Diarrhoea & $86(74.8)$ & $37(32.5)$ & $132(76.3)$ & $54(31.0)$ \\
\hline Nausea & $38(33.0)$ & 19 (16.7) & 53 (30.6) & $20(11.5)$ \\
\hline Vomiting & $32(27.8)$ & $16(14.0)$ & $39(22.5)$ & $14(8.0)$ \\
\hline Abdominal pain & $13(11.3)$ & $5(4.4)$ & $20(11.6)$ & $16(9.2)$ \\
\hline Weight loss & $18(15.7)$ & $8(7.0)$ & $16(9.2)$ & $5(2.9)$ \\
\hline
\end{tabular}

Predisposition to intestinal events was defined as a history of, and/or presence at baseline of, diarrhoea, bloating, constipation and/or incontinence. Data are $\mathrm{n}(\%)$ of patients with $\geq 1$ such adverse event reported over 52 weeks (or until 28 days after last trial drug intake for patients who discontinued trial drug before week 52). Adverse events shown are those reported in $>10 \%$ of patients in either the nintedanib or placebo group by single MedDRA preferred terms in the system organ class 'gastrointestinal disorders', except for abdominal pain, which was based on a MedDRA high-level term (related preferred terms), and weight loss, which was based on the MedDRA preferred terms 'weight decreased' and 'abnormal loss of weight'.

MedDRA, Medical Dictionary for Regulatory Activities.

\section{Adverse events in patients with $\mathrm{PH}$}

At baseline, 23 patients in the nintedanib group and 29 patients in the placebo group had $\mathrm{PH}$. Among the patients with $\mathrm{PH}$, one patient in each treatment group had an adverse event of $\mathrm{PH}$ (indicating worsening of $\mathrm{PH}$ ) during the trial. There were no events of cardiac failure or pulmonary haemorrhage in patients with $\mathrm{PH}$ taking nintedanib. In the nintedanib and placebo groups, respectively, serious adverse events occurred in higher proportions of patients with $\mathrm{PH}(34.8 \%$ and $34.5 \%)$ than without $\mathrm{PH}(23.0 \%$ vs $20.1 \%)$. In the nintedanib group, the proportions of patients with gastrointestinal adverse events were similar between those with and without PH (online supplementary table S9).

\section{Other adverse events}

The proportions of patients with hepatic adverse events and elevations in hepatic enzymes and bilirubin were greater in patients treated with nintedanib than placebo (table 5). Elevation in alanine aminotransferase (ALT) and/or aspartate aminotransferase (AST) to $\geq 3 \times$ upper limit of normal was reported in $4.9 \%$ of patients in the nintedanib group and $0.7 \%$ of patients in the placebo group.

Bleeding adverse events were reported in $11.1 \%$ of patients in the nintedanib group and $8.3 \%$ of patients in the placebo group. Epistaxis (2.8\% nintedanib and 3.8\% placebo) and contusion (2.4\% nintedanib and $1.0 \%$ placebo) were the most frequently reported bleeding events. Serious bleeding adverse events occurred in $1.4 \%$ and $0.7 \%$ of patients in the nintedanib and placebo groups, respectively.

Hypertension was reported in $4.9 \%$ and $1.7 \%$ of patients in the nintedanib and placebo groups, respectively. Other cardiovascular adverse events occurred at a similar low frequency between the treatment groups (online supplementary table S10). Scleroderma renal crisis was reported in one patient (in the nintedanib group).

\section{DISCUSSION}

We used data from the SENSCIS trial to characterise the safety and tolerability profile of nintedanib in patients with SSc-ILD. The adverse event profile of nintedanib in patients with SScILD was consistent with that observed in patients with IPF, with 
Table 5 Hepatic adverse events and elevations in hepatic enzymes and bilirubin in the SENSCIS trial

\begin{tabular}{|c|c|c|}
\hline & $\begin{array}{l}\text { Nintedanib } \\
(\mathrm{n}=288)\end{array}$ & $\begin{array}{l}\text { Placebo } \\
(n=288)\end{array}$ \\
\hline Hepatic adverse event* & $40(13.9)$ & $9(3.1)$ \\
\hline \multicolumn{3}{|l|}{ Elevation in ALT and/or AST } \\
\hline$\geq 3 \times$ ULN & $14(4.9)$ & $2(0.7)$ \\
\hline$\geq 5 \times$ ULN & $3(1.0)$ & $1(0.3)$ \\
\hline$\geq 8 \times$ ULN & 0 & $1(0.3)$ \\
\hline $\begin{array}{l}\text { Elevation in ALT and/or AST } \geq 3 \times \text { ULN and in } \\
\text { bilirubin } \geq 2 \times \text { ULN }\end{array}$ & 0 & 0 \\
\hline \multicolumn{3}{|l|}{ Elevation in total bilirubin } \\
\hline$\geq 1.5 \times$ ULN & $1(0.3)$ & 0 \\
\hline$\geq 2 \times$ ULN & $1(0.3)$ & 0 \\
\hline \multicolumn{3}{|l|}{ Elevation in alkaline phosphatase } \\
\hline$\geq 1.5 \times$ ULN & $10(3.5)$ & $3(1.0)$ \\
\hline$\geq 2 \times$ ULN & $3(1.0)$ & 0 \\
\hline \multicolumn{3}{|c|}{$\begin{array}{l}\text { Data are } \mathrm{n}(\%) \text { of patients with } \geq 1 \text { such event reported over } 52 \text { weeks (or until } 28 \text { day } \\
\text { last trial drug intake for patients who discontinued trial drug before week 52). } \\
\text { *Based on the standardised MedDRA query 'liver related investigations, signs and } \\
\text { symptoms' (broad definition). } \\
\text { ALT, alanine aminotransferase; AST, aspartate aminotransferase; MedDRA, Medical } \\
\text { Dictionary for Regulatory Activities; ULN, upper limit of normal. }\end{array}$} \\
\hline
\end{tabular}

diarrhoea being the most common adverse event. ${ }^{489}$ Other gastrointestinal adverse events (nausea, vomiting and abdominal pain) and weight loss were also more common in patients treated with nintedanib than placebo.

SSc is commonly associated with gastrointestinal problems such as oesophageal dysmotility, gastro-oesophageal reflux disease, faecal incontinence and small bowel involvement. ${ }^{7}$ In both the nintedanib and placebo groups, gastrointestinal adverse events were more frequently reported in the SENSCIS trial than in the INPULSIS trials in patients with IPF. ${ }^{8}$ However, permanent discontinuations of nintedanib due to diarrhoea occurred in similar proportions of nintedanib-treated patients in SENSCIS as in INPULSIS (6.9\% vs 4.4\%, respectively). Of note, gastrointestinal adverse events were not more frequent in patients with a predisposition to them, indicating that underlying gastrointestinal disorders should not preclude patients from being treated with nintedanib. The low rate of permanent discontinuation of nintedanib due to gastrointestinal adverse events suggests that the recommendations given to the investigators for the management of adverse events in the SENSCIS trial were effective in managing these events and should be implemented in clinical practice to help maintain patients on treatment.

At baseline, almost half of the patients in the SENSCIS trial were taking mycophenolate, which may be associated with gastrointestinal adverse events. ${ }^{10}$ Previous analyses have shown that the adverse event profile of nintedanib (including the proportion of patients with diarrhoea) was generally similar between subgroups by mycophenolate use, and permanent treatment discontinuations were not more common in nintedanibtreated patients taking mycophenolate, with the caveat that patients taking mycophenolate at baseline had tolerated it for at least 6 months before entering the trial. ${ }^{11}$

The proportion of nintedanib-treated patients who had at least one dose reduction was higher in the SENSCIS trial than in the INPULSIS trials in patients with IPF (40.6\% vs $27.9 \%)$, while the proportion who prematurely discontinued trial medication over 52 weeks was lower $(19.4 \%$ vs $24.5 \%) .{ }^{8}$ As observed in the INPULSIS trials, ${ }^{12}$ the rate of decline in FVC was similar in nintedanib-treated patients irrespective of dose adjustments, suggesting that the dose adjustments used to manage adverse events did not reduce the efficacy of nintedanib in reducing the progression of ILD. However, since these subgroups were defined based on dose adjustments made during treatment, this observation should not be misinterpreted as meaning that patients should be started at a dose of $100 \mathrm{mg}$ two times per day. A dose finding study in patients with IPF identified nintedanib $150 \mathrm{mg}$ two times per day as the optimal dose for reducing the rate of decline in FVC. ${ }^{13}$ While some patients may experience adverse events that require a dose reduction, it is not possible to identify these patients before treatment is initiated and, as such, patients (other than those with mild hepatic impairment ${ }^{14}$ ) should initiate treatment at a dose of $150 \mathrm{mg}$ two times per day to ensure that they receive the optimal drug effect. In patients with IPF, a positive relationship was observed between exposure to nintedanib and elevations in liver enzymes (ALT and/or AST $\geq 3 \times$ ULN). Females may have a higher exposure-adjusted risk of ALT and/or AST $\geq 3 \times$ ULN, but with a low overall occurrence. ${ }^{14}$ Higher age, lower weight and Asian race were associated with small to moderate increases in nintedanib exposure, which were within the range of interpatient variability and did not warrant a priori dose adjustment. ${ }^{15} 16$

Nintedanib is an inhibitor of the vascular endothelial growth factor receptor (VEGFR) ${ }^{3}$ and VEGFR inhibition is associated with an increased risk of bleeding. ${ }^{17}$ Patients at high risk of bleeding have been excluded from clinical trials of nintedanib, although use of low-dose antithrombotics and analgesics was permitted in the SENSCIS trial. In the SENSCIS trial, bleeding adverse events were reported in $11.1 \%$ of patients in the nintedanib group compared with $8.3 \%$ in the placebo group. Vascular endothelial growth factor promotes wound healing through several mechanisms, including collagen deposition, angiogenesis and epithelialisation. ${ }^{18}$ Thus, it is notable that there was no difference between nintedanib and placebo in net digital ulcer burden. ${ }^{5}$ No indication of aggravation of $\mathrm{PH}$, cardiac failure or pulmonary haemorrhage was observed in patients with $\mathrm{PH}$ treated with nintedanib.

As observed in previous studies, ${ }^{9}$ hepatic adverse events and liver test abnormalities were more common in patients treated with nintedanib than placebo in the SENSCIS trial. Most of the observed elevations in ALT and/or AST were $<3$ times the upper limit of normal. It is recommended that liver function tests be conducted prior to initiation of treatment with nintedanib, at regular intervals during the first 3 months of treatment and periodically thereafter or as clinically indicated. ${ }^{14}$ No patient met criteria for Hy's law.

Although long-term data on the use of nintedanib in patients with SSc-ILD are not yet available, data from the open-label extension of the INPULSIS trials, INPULSIS-ON, suggest that the safety and tolerability of nintedanib are maintained with long-term use. ${ }^{19}$ In addition, pharmacovigilance data collected in patients with IPF, based on over 80000 patient-years of exposure, suggest that the safety and tolerability of nintedanib in clinical practice is consistent with that observed in clinical trials. ${ }^{20}$

Limitations of these analyses include incomplete information on the procedures used by the investigators used to manage gastrointestinal adverse events and on adverse events reported in patients taking specific comedications (other than mycophenolate). When comparing results between the INPULSIS and SENSCIS trials, differences in the patient populations need to be kept in mind, particularly that IPF is a non-systemic disease that tends to present in male ex-smokers in the sixth or seventh decade of life, while SSc is a systemic multiorgan autoimmune disease that is more common in women, with a peak onset in middle age, and that the patients in the SENSCIS trial had a lower mean body mass index. 
In conclusion, these data from the SENSCIS trial demonstrate that the adverse event profile of nintedanib in patients with SSc-ILD is consistent with its established safety and tolerability profile in patients with IPF. Adverse events associated with nintedanib were generally consistent across subgroups defined by age, sex, race and weight, although nausea, vomiting and hepatic adverse events were reported more frequently in female than male patients. The effect of nintedanib on reducing the rate of decline in FVC was similar irrespective of dose adjustments used to manage adverse events. Management of adverse events using symptomatic therapies and dose adjustment is important to minimise the impact of adverse events and to help patients remain on therapy.

\section{Author affiliations}

${ }^{1}$ Scleroderma Research Consultants, LLC, Aiken, South Carolina, USA

${ }^{2}$ National Heart and Lung Institute, Imperial College London, London, UK

${ }^{3}$ National Institute for Health Research Clinical Research Facility, Royal Brompton Hospital, London, UK

${ }^{4}$ Keck School of Medicine, University of Southern California, Los Angeles, California, USA

${ }^{5}$ Respiratory Institute, Cleveland Clinic, Cleveland, Ohio, USA

${ }^{6}$ University of Texas Houston Medical School, Houston, Texas, USA

7 Department of Pulmonary Medicine and Oncology, Graduate School of Medicine, Nippon Medical School, Tokyo, Japan

${ }^{8}$ Division of Rheumatology, Johns Hopkins University School of Medicine, Baltimore, Maryland, USA

${ }^{9}$ Interstitial and Rare Lung Disease Unit, Department of Pneumology, Ruhrlandklinik, University Hospital Essen, Essen, Germany

${ }^{10}$ Boehringer Ingelheim Pharma GmbH \& Co. KG, Biberach, Germany

${ }^{11}$ Boehringer Ingelheim Pharmaceuticals, Inc, Ridgefield, Connecticut, USA

${ }^{12}$ Boehringer Ingelheim (Schweiz) GmbH, Basel, Switzerland

${ }^{13}$ Boehringer Ingelheim International $\mathrm{GmbH}$, Ingelheim am Rhein, Germany

${ }^{14}$ Department of Rheumatology, University Hospital Zurich, Zurich, Switzerland

Twitter Shervin Assassi @ShervinAssassi

Acknowledgements We thank the patients who participated in this trial. Writing assistance, supported financially by Boehringer Ingelheim, was provided by Elizabeth $\mathrm{Ng}$ and Wendy Morris of FleishmanHillard Fishburn, London, UK, during the development of this article. The authors were fully responsible for all content and editorial decisions, were involved at all stages of development and provided their approval on the final version. Boehringer Ingelheim was given the opportunity to review the manuscript for medical and scientific accuracy, as well as intellectual property considerations.

Contributors JRS, TMM, KH, SA, AA, LKH and OD were involved in data acquisition. All authors were involved in the analysis and interpretation of the data and in drafting the manuscript.

Funding The SENSCIS trial was funded by Boehringer Ingelheim.

Competing interests JRS reports personal fees from Atlantic, Bayer, Blade, Boehringer Ingelheim, Camurus, Corbus, DRG, Eicos, Eiger Pharmaceuticals, EMD Serono, Guidepoint, Indalo, Mitsubishi and Xenikos; and stock ownership or options in BriaCell and Pacific Therapeutics. TMM reports grants and personal fees from GlaxoSmithKline and UCB, and personal fees from Apellis, Bayer, Biogen Idec, Blade, Boehringer Ingelheim, Bristol-Myers Squibb, Galapagos, Galecto, Indalo, Novartis, Respivent, Roche and Trevi. KBH reports grants and personal fees from Actelion Pharmaceuticals, Boehringer Ingelheim and United Therapeutics; personal fees from Bayer; and grants from Genentech, Eiger BioPharmaceuticals and Reata Pharmaceuticals. SA reports grants, personal fees and other remuneration from Boehringer Ingelheim; grants from Bayer, Biogen Idec and Momenta; and personal fees from Medscape, Integrity Continuing Education and Corbus. AA reports personal fees and other remuneration from Boehringer Ingelheim, Taiho Pharmaceutical and Toray; personal fees from Asahi Kasei Pharma; and other remuneration from Shionogi \& Co., Ltd, and aTyr Pharma. LKH reports other remuneration from Boehringer Ingelheim (investigator of SENSCIS trial). UC reports personal fees and non-financial support from Boehringer Ingelheim and Roche; and personal fees from AstraZeneca, Fibrogen, Novartis and Pliant Therapeutics. UVW, VK, MG and MA are employees of Boehringer Ingelheim. OD reports grants and personal fees from Actelion, Bayer, Boehringer Ingelheim and Mitsubishi; personal fees from AbbVie, Acceleron Pharma, Anamar, Amgen, Baecon Discovery, Blade Therapeutics, Catenion, CSL Behring, ChemomAb, Curzion Pharmaceuticals, Ergonex, Galapagos NV, Glenmark Pharma, GlaxoSmithKline, Inventiva, Italfarmaco, IQVIA, Lilly, Medac, Medscape, Menarini, Mepha, Merck Sharp \& Dohme, Novartis, Roche, Sanofi, Target BioScience and UCB; personal fees and non-financial support from Pfizer; and patent US8247389. TMM, KBH, AA and OD were members of the SENSCIS trial steering committee.

Patient and public involvement Patients and/or the public were not involved in the design, or conduct, or reporting, or dissemination plans of this research.

\section{Patient consent for publication Not required.}

Ethics approval The study protocol was reviewed and approved by the Independent Ethics Committees and/or Institutional Review Boards of the participating centres. Written informed consent was obtained from all patients before study entry.

Provenance and peer review Not commissioned; externally peer reviewed.

Data availability statement Data are available upon reasonable request (see online supplementary files).

Open access This is an open access article distributed in accordance with the Creative Commons Attribution 4.0 Unported (CC BY 4.0) license, which permits others to copy, redistribute, remix, transform and build upon this work for any purpose, provided the original work is properly cited, a link to the licence is given, and indication of whether changes were made. See: https://creativecommons.org/ licenses/by/4.0/.

\section{ORCID iDs}

James R Seibold http://orcid.org/0000-0001-5187-3141

Shervin Assassi http://orcid.org/0000-0002-8059-9978

Oliver Distler http://orcid.org/0000-0002-0546-8310

\section{REFERENCES}

1 van den Hoogen F, Khanna D, Fransen J, et al. 2013 classification criteria for systemic sclerosis: an American College of Rheumatology/European League against Rheumatism collaborative initiative. Ann Rheum Dis 2013;72:1747-55.

2 Elhai M, Meune C, Boubaya M, et al. Mapping and predicting mortality from systemic sclerosis. Ann Rheum Dis 2017:76:1897-905.

3 Wollin L, Wex E, Pautsch A, et al. Mode of action of nintedanib in the treatment of idiopathic pulmonary fibrosis. Eur Respir J 2015;45:1434-45.

4 Richeldi L, du Bois RM, Raghu G, et al. Efficacy and safety of nintedanib in idiopathic pulmonary fibrosis. N Engl J Med 2014;370:2071-82.

5 Distler 0 , Highland KB, Gahlemann M, et al. Nintedanib for systemic sclerosisassociated interstitial lung disease. N Engl J Med 2019:380:2518-28.

6 Flaherty KR, Wells AU, Cottin V, et al. Nintedanib in progressive fibrosing interstitial lung diseases. N Engl J Med 2019;381:1718-27.

7 McMahan ZH, Hummers LK. Gastrointestinal involvement in systemic sclerosis: diagnosis and management. Curr Opin Rheumatol 2018;30:533-40.

8 Corte T, Bonella F, Crestani B, et al. Safety, tolerability and appropriate use of nintedanib in idiopathic pulmonary fibrosis. Respir Res 2015;16:116.

9 Lancaster L, Crestani B, Hernandez P, et al. Safety and survival data in patients with idiopathic pulmonary fibrosis treated with nintedanib: pooled data from six clinical trials. BMJ Open Respir Res 2019:6:e000397.

10 Omair MA, Alahmadi A, Johnson SR. Safety and effectiveness of mycophenolate in systemic sclerosis. A systematic review. PLoS One 2015;10:e012420.

11 Highland KB, Distler O, Kuwana M, et al. Efficacy and safety of nintedanib in patients with systemic sclerosis-associated interstitial lung disease treated with mycophenolate: subgroup analysis of the SENSCIS trial. Lancet Respir Med in press

12 Maher TM, Inoue Y, Harai Case A. Effect of dose reductions and/or interruptions on the efficacy of nintedanib in patients with idiopathic pulmonary fibrosis (IPF): subgroup analysis of the INPULSIS trials, 2017. Poster presented at the American Thoracic Society International Conference. Available: http://www.ildposters2017.com/ pdf/INPULSIS_Maher.pdf

13 Richeldi L, Costabel U, Selman M, et al. Efficacy of a tyrosine kinase inhibitor in idiopathic pulmonary fibrosis. N Engl J Med 2011;365:1079-87.

14 Boehringer Ingelheim. Ofev prescribing information, 2019. Available: https://www. accessdata.fda.gov/drugsatfda_docs/label/2019/205832s012lbl.pdf [Accessed 25 Nov 2019].

15 Wind S, Schmid U, Freiwald $M$, et al. Clinical pharmacokinetics and pharmacodynamics of nintedanib. Clin Pharmacokinet 2019;58:1131-47.

16 Schmid U, Doege C, Dallinger $C$, et al. Population pharmacokinetics of nintedanib in patients with idiopathic pulmonary fibrosis. Pulm Pharmacol Ther 2018:48:136-43.

17 Schmidinger M. Understanding and managing toxicities of vascular endothelial growth factor (VEGF) inhibitors. EJC Supp/ 2013;11:172-91.

18 Bao P, Kodra A, Tomic-Canic M, et al. The role of vascular endothelial growth factor in wound healing. J Surg Res 2009;153:347-58.

19 Crestani B, Huggins JT, Kaye M, et al. Long-term safety and tolerability of nintedanib in patients with idiopathic pulmonary fibrosis: results from the open-label extension study, INPULSIS-ON. Lancet Respir Med 2019:7:60-8.

20 Boehringer Ingelheim. Arthritis Advisory Committee Briefing materials. Nintedanib soft capsules. Indication: treatment of systemic sclerosis-associated interstitial lung disease, 2019. Available: https://www.fda.gov/media/129233/download [Accessed 17 Dec 2019]. 